\title{
Corporate entrepreneurship level: a case study of contractors in Indonesia
}

\author{
Harijanto Setiawan ${ }^{1, *}$ and Bilge Erdogan ${ }^{2}$ \\ ${ }^{1}$ Universitas Atma Jaya Yogyakarta, Civil Engineering Department, 55281 Yogyakarta, Indonesia \\ ${ }^{2}$ Heriot Watt University, School of Engineering, Geoscience, Infrastructure and Society, EH14 4 AS, \\ Edinburgh, UK
}

\begin{abstract}
Contractors need to assess their capability to implement corporate entrepreneurship (CE), in order to develop the proper corporate strategy based on CE. This study is aimed to assess the capability level of contractors to implement $\mathrm{CE}$ using corporate entrepreneurship capability model (CECM). CECM has been developed based on the concept of Capability Maturity Model (CMM). The capability level of contractors to implement $\mathrm{CE}$ is assessed using 21 indicators which are classified into five dimensions: autonomy, competitive aggressiveness, innovativeness, proactiveness and risk-taking. CECM divides the capability of contractors to implement $\mathrm{CE}$ into four levels: initial, repeatable, managed and optimized. This study carried out a case study of 2 big contractors in Indonesia. The data was collected using a questionnaire and then an arithmetic mean of each indicator was calculated to determine the capability level of contractors to implement CE. The case study found the highest level of capability to implement $\mathrm{CE}$ is reached in two different indicators: innovativeness and proactiveness, meanwhile the lowest level for both contractors is risk-taking. This study also found the capability level of both contractors are at a level between managed and optimized.
\end{abstract}

\section{Introduction}

The established companies need a strategy to survive competition and corporate entrepreneurship (CE) has been considered as a strategy to enable them to be a success in the competition [1-5]. Contractors have been considered as the construction companies that counter high levels of competition, therefore, they need to implement the right strategy in order to be a success in the competition. In this condition, CE can be established as a strategy that can be adopted to ensure the success of contractor businesses. However, van Wyk and Adonisi [6] mentioned that the model of CE cannot be generalized to all business sectors, therefore, the specific model of CE for contractor businesses needs to be explored in a specific way. Comparing to other companies, contractors run their business in a unique way.

Contractors have been considered as the Project-Based Firms (PBFs) that deliver the project as a unique end product. Projects are designed specifically based on the client's

* Corresponding author: haris@mail.uajy.ac.id 
needs. Contractors as PBFs need to manage both business and project that have different characteristics. Projects usually have temporary and unique activities, while business processes cover repetitive activities [7]. Therefore contractors need to manage a temporary project's organization within the permanent firm's organization [7-11].

In order to develop the corporate strategy based on the CE concept, contractors need to understand the entrepreneurial characteristics of their company. Then a strategy can be developed based on their existing entrepreneurial characteristics. This study is focused on assessing the existing entrepreneurial level of contractors through case studies of two big contractors in Indonesia. The contractors in the case studies are a privately-owned contractor and a state-owned contractor. The case studies used Corporate Entrepreneurship Capability Model (CECM) that has been developed by Setiawan [12] as the instrument to assess the capability level of both contractors to implement CE.

\section{Corporate entrepreneurship capability model (CECM)}

CECM has been used to assess the corporate entrepreneurial level of contractors in the case studies. CECM has been developed by Setiawan [12] by adopting the concept of Capability Maturity Model (CMM). Initially in 1991 CMM was developed by the Software Engineering Institute, Carnegie Mellon University [13]. CECM consists of two main basic components, those are the indicators of $\mathrm{CE}$ and the capability levels of contractors.

As the indicators of CE, CECM uses twenty-one key factors that are considered as the most important factors of CE [14]. These indicators are categorized under five dimensions of CE: autonomy, competitive aggressiveness, innovativeness, proactiveness and risktaking, that are proposed by Lumpkin and Dess [15]. The twenty-one indicators of CECM under five dimensions of CE can be explained as follows.

1. Autonomy

The entrepreneurial contractors give autonomy to the staff individually or in groups to do independent actions such as accessing information, communication both horizontally and vertically, proposing suggestions for projects and the company, and planning and managing projects.

2. Competitive aggressiveness

The entrepreneurial contractors do several actions to outperform the competitors. They need to maintain a good relationship with clients and to act as a problem solver for their clients, as well as to build and maintain clients' confidence in trustworthiness and reliability of the company. The contractors must be concerned about better quality rather than cheaper prices.

3. Innovativeness

The entrepreneurial contractors need to be actively generating innovations that are directed to meet clients' demands and to build the projects efficiently and effectively. In order to spur the innovations, the contractors need to carry out research and development activities, programs that spark innovation need to be supported and the staff needs to be challenged to become innovative.

4. Proactiveness

In running the business, contractors are required to proactively seize business opportunities. They need to carry out marketing activities and look ahead for future demands. Contractors also need to expand their market into new segments and new areas. Business diversification is another proactive action of contractors to find new business opportunities and to expand their business.

5. Risk taking

The entrepreneurial contractors need to be risk takers. They need to take a bold action to accept projects from new clients and to take projects with several risks such as 
financial risk, technical risk as well as social risk. They also need to be a risk taker to introduce innovations.

CECM categorizes the capability of contractors to implement CE into four levels. These four capability levels were chosen after reviewing CMM as the initial model and several of the existing capability maturity models. This decision also considers characteristics of contractors and CE concept. The four capability levels in CECM are arranged in sequence from 1 to 4 , from the lowest level to the top level. The four capability levels for CECM are defined as follows.

- Level 1: INITIAL

The need of CE to support the success of contractor businesses is not realized by the contractor, therefore, no policies, no formal processes, and no structured approaches for the implementation of $\mathrm{CE}$ are in place. The $\mathrm{CE}$ is implemented only because of selfinterest and individual efforts of the people working in the company.

- Level 2: REPEATABLE

Awareness of the importance of CE to support the success of contractor businesses has emerged, however, there is still a lack of a standardized process for the implementation of CE. In order to achieve earlier success for similar implementations, the process of CE implementation is established and repeated.

- Level 3: MANAGED

The process for implementing CE has been defined, implemented, and controlled consistently because the need of CE to support the success of contractor businesses has been realized. Top management fully understands the benefit of $\mathrm{CE}$ to support the business success, therefore, the implementation of CE is fully supported.

- Level 4: OPTIMIZED

The CE has been fully implemented and is managed well. The process for CE implementation has been standardized and is continuously evaluated. Continuous improvement is enabled based on the feedback from the implementation of the $\mathrm{CE}$ indicators. The contractors have gained the benefits from the implementation of CE.

\section{Research methodology}

\subsection{Research process}

The process started by determining big contractors that will become the objects of the case studies. Big contractors are chosen to participate in this case study because they are considered as the contractors that determine several strategies that are in accordance with the concept of CE. Another important criteria for the contractors that are involved in the case studies is the sustainability of their business because the findings of this study will be generated based on their experiences to run their business successfully.

The case study is started by identifying a list of eligible big contractors to be involved in the case studies. Then the contractors on the list were approached formally and informally to get the permission to carry out a case study in their company. Finally, two contractors agree to be involved in a case study. The next step, each contractor was asked to appoint a person in charge to facilitate this case study. The persons in charge of each contractor are the Director of Human Resources, Personnel Administration, and General Affairs for contractor 1 and Human Capital Manager for contractor 2.

Later on, the case studies were conducted following the process that was divided into three stages, namely preparation, execution, and post execution, then finally after the last stage was completed, the result was found. The detail of each stage was outlined in Figure 1. 


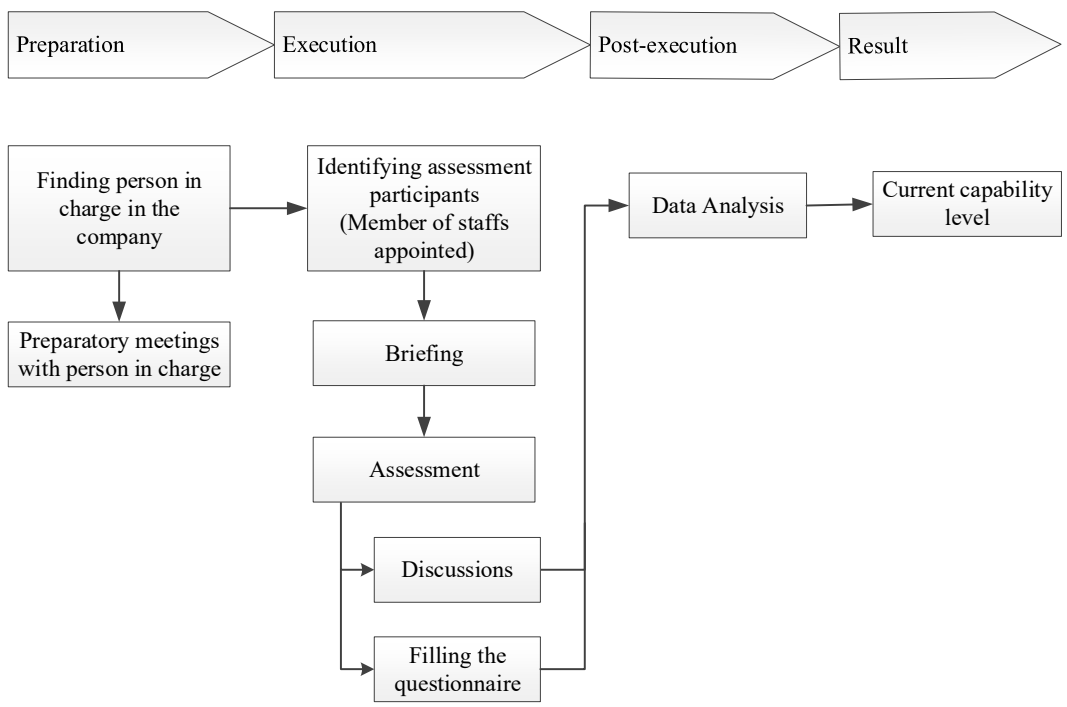

Fig. 1. The procedure of the case studies.

\subsection{Data analysis}

The data analysis process that was adopted in the case studies is shown in the diagram of Figure 2. The diagram shows that this study adopted both quantitative and qualitative analysis. The quantitative approach is used to analyse data from the questionnaire, while the qualitative approach is used to analyse data from the discussions that are intended to provide deeper explanations of the findings from the quantitative data analysis.

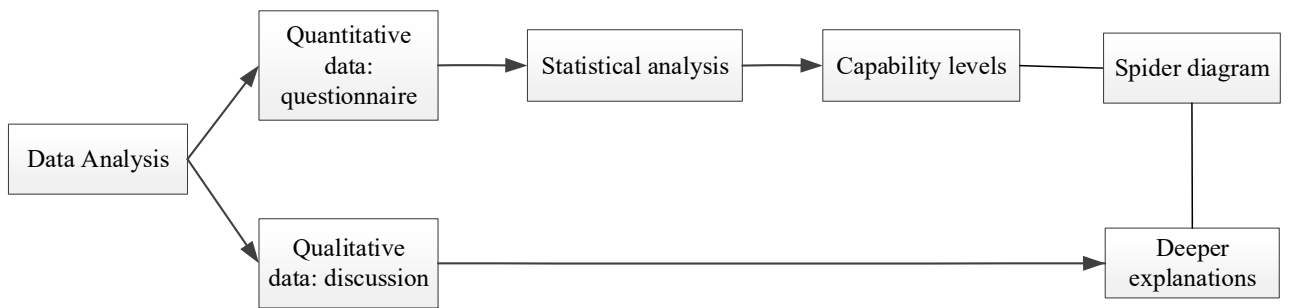

Fig. 2. Data analysis.

\subsubsection{Quantitative data analysis}

The questionnaire was used as an instrument to gather the quantitative data. The questionnaire consists of 21 questions that represent 21 indicators of $\mathrm{CE}$ that has been developed by Setiawan and Erdogan [14]. Four answer choices in each question in the questionnaire represent four capability levels of contractors to implement CE.

The quantitative data gathered from the questionnaire was analysed by calculating the arithmetic mean which is the average of all numbers in a set of data. The arithmetic mean will range between a minimum of 1 that represents the lowest level and a maximum of 4 that represents the highest level.

In this study, the arithmetic mean is used to determine the capability level of contractors to implement $\mathrm{CE}$ in three different issues as follows:

1 The capability level to implement each indicator of CE which is shown by means of 
each indicator.

2 The capability level to implement each dimension of CE which is shown by means of groups of indicators.

3 The capability level to implement CE thoroughly that is shown by means of all indicators.

In order to provide a clearer picture of the level of the contractor to implement $\mathrm{CE}$, the arithmetic mean of each indicator, as well as each dimension of CE are plotted in two different spider diagrams.

\subsubsection{Qualitative data analysis}

The deeper overview about the implementation of $\mathrm{CE}$ in both contractors participating in the case study will accompany the finding of quantitative analysis that presents their capability levels. The qualitative analysis was adopted to explore the deeper overview related to the implementation of $\mathrm{CE}$ in every participating contractor.

The qualitative data was collected through discussions with the staff of both contractors that participated in the case studies. In order to facilitate the qualitative data analysis, the discussions were fully audio-recorded and then fully transcribed. The qualitative analysis was started by reading the transcripts carefully several times. During this initial step, the main ideas of each discussion were attempted to be captured. After the main ideas were captured, the transcripts were re-read, while the important points that emerged from the discussions were noted.

\section{Research findings}

\subsection{Case study 1}

\subsubsection{Background of contractor 1}

Contractor 1 is a general contractor that is privately owned which has been established since 1970. This contractor eventually is recognised as a building specialist. For almost half a century, this contractor has successfully sustained the business and even grown the business rapidly. Now, this contractor is considered as a leading building contractor in Indonesia.

This contractor has become a public company through a listing on the Jakarta Stock Exchange since 2006. On average every year this contractor obtains around thirty-five building projects. Nowadays this contractor employs around 400 engineers and in total, the staff members are over 1,100 .

The case study in this contractor has been attended by thirteen staff members at the level of engineers. These thirteen staff are from different position levels such as director, manager, and engineer. They have education backgrounds at the level of bachelor and master degree. The working experiences in this company ranges from 1 year to 23 years, while their involvement in the construction industry in total ranges from 7 years to 32 years.

\subsubsection{Corporate entrepreneurship capability level of Contractor 1}

The results of case study 1 show that contractor 1 , as a whole, is at the level of corporate entrepreneurship capability between 3 and 4 with mean 3.21. The highest level of their 
capability is reached by innovativeness, while the lowest level is risk-taking. The spider diagrams for means of indicators and group of indicators are prepared to give a better picture of about the result. The spider diagrams are shown in Figure 3.
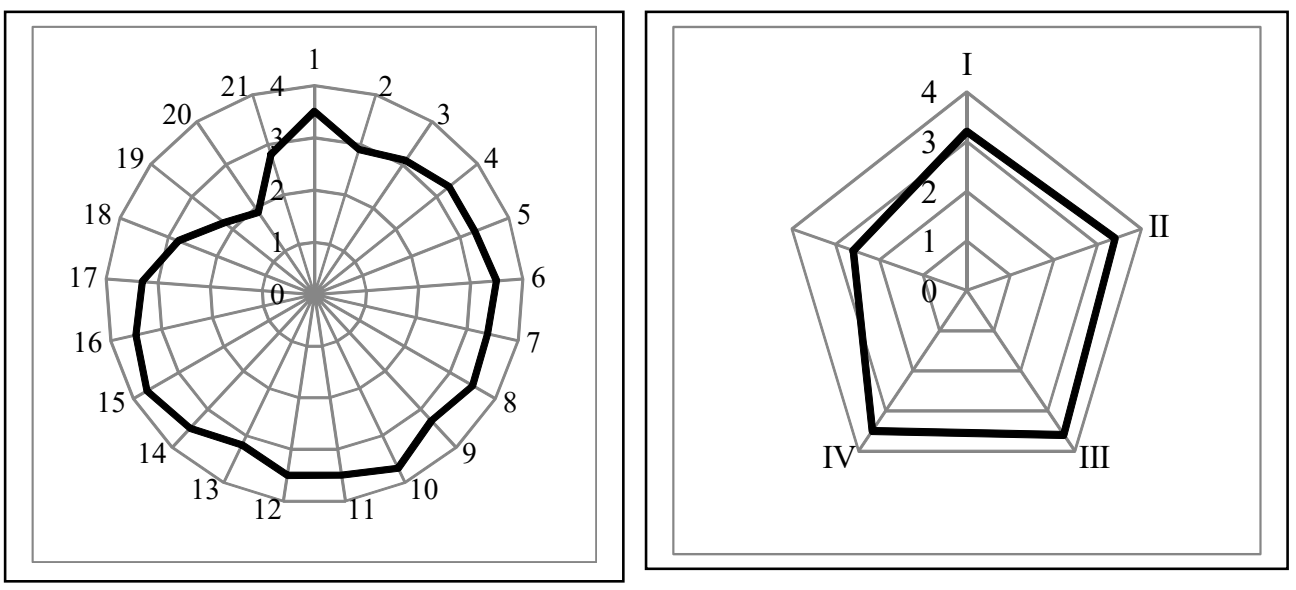

Fig. 3. Capability level of contractor 1.

This finding is in accordance with the real condition of this contractor that has been explored through discussions with the participants. This contractor has seriously carried out programmes that support the creation of innovation. The programme called innovation day' is one of the examples. However, this contractor does not concern themselves with risk-taking for getting new projects because repeat orders from previous clients is the main source of the projects that come to this contractor

\subsection{Case study 2}

\subsubsection{Background of contractor 2}

Contractor 2 is a state-owned contractor that has been established since 1961. Initially, this contractor has specialization in the projects that relate to water such as land reclamation, dredging, harbours, and irrigation. Since 1973 this contractor expanded its status to become a general contractor, therefore, it engaged in a wider range of construction projects. This contractor works on a variety of construction projects such as highways, bridges, ports, airports, and buildings. Currently, this contractor becomes one of the market leaders in Indonesia's construction industry, even its shares have been listed on the Indonesian Stock Exchange (IDX). At the moment, this contractor is supported by around 1077 staff members; of which 817 of them are engineers.

The head office of this contractor is in Jakarta, in running its business, this contractor is supported by 30 branch offices that spread across several cities in Indonesia. In order to reach overseas market segments, in 2006 this contractor opened overseas branch-offices in Dubai and Jeddah. This contractor also carried out business expansions in a variety of new areas such as precast, realty, energy and toll roads.

In this case study, thirteen members of staff from contractor 2 participated. The respondents from this contractor are from different levels. They are from general manager to staff who work in the head office, also project managers and site managers who work in the project site. The education background of the respondents is Bachelor and Master 
degrees with working experiences in this contractor ranging from 3 years to 26 years, while their involvement in the construction industry is ranging from 7 years to 26 years.

\subsubsection{Corporate entrepreneurship capability level of contractor 2}

The result of the quantitative analysis shows that, as a whole, the capability of contractor 2 to implement $\mathrm{CE}$ is at a level between 3 and 4 with mean 3.25. Furthermore, to provide a better picture of the result, the mean of each indicator and each group of indicators for this contractor are plotted in the spider diagrams as can be seen in Figure 4.
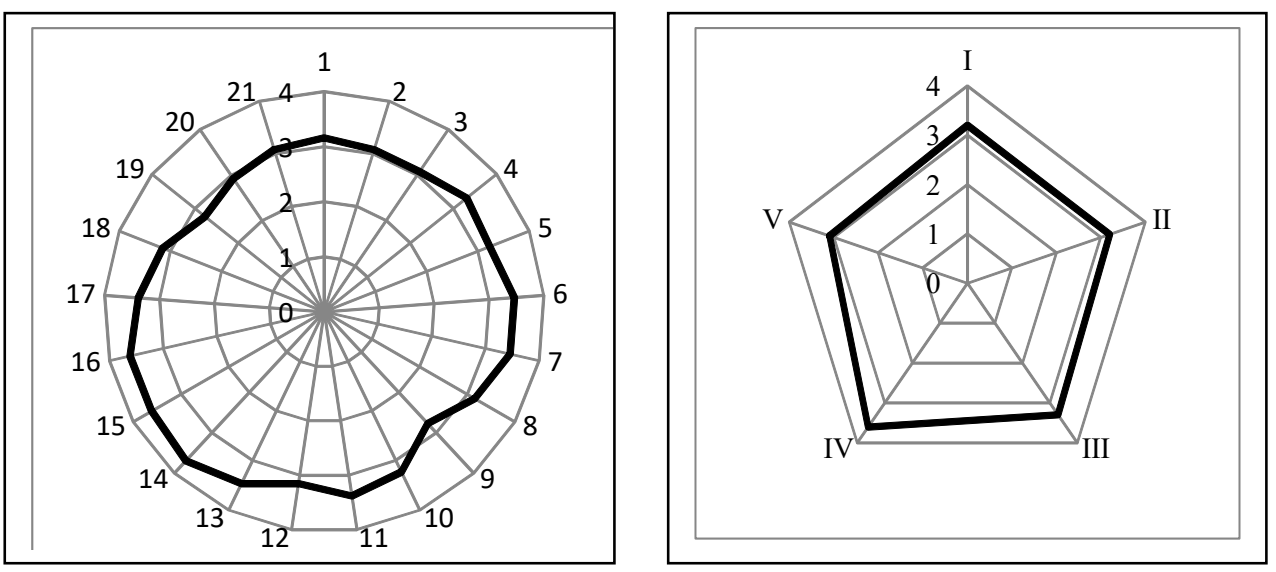

Fig. 4. Capability level of contractor 2 .

Among all indicators, the highest capability level of this contractor is reached in proactiveness while the lowest level is risk-taking. This result is supported by the finding from the discussion that this contractor has several robust programmes to support proactiveness. Thirty branch offices that are spread all over Indonesia and 2 overseas branch offices show the proactive action of this contractor to expand its market both locally and globally. The business diversification that has been carried out such as property developer, pre-cast concrete fabricator, and hydro power plants is another embodiment of the proactiveness of this contractor.

\section{Conclusion and discussion}

The results from the two case studies have been investigated and several interesting and important findings were identified.

1. Both contractors in the case study are at the capability level to implement CE between 3 (managed) and 4 (optimized) but their means are slightly different. The mean of contractor 1 is 3.21 , while contractor 2 has mean 3.25 .

2. In these case studies, risk-taking is the dimension at the lowest level among five dimensions of $\mathrm{CE}$ for both contractors. Two issues can be considered as a background for this finding. First, contractors run very high-risk businesses, therefore they tend to be very careful about risk-taking. The failure of their business can result in commercial fatality such as bankruptcy. In this business situation, contractors tend to be very careful to take a risk. Second, the participants in these case studies are the leading contractors in Indonesia that have been well established in their business, therefore, they are not concerned to take a risk to get a project. 
3. The highest capability level of each contractor is different, it's shown that each contractor implements a different strategy to run the business. The highest capability level of contractor 1 is innovativeness, while contractor 2 has highest capability level in proactiveness. The strategies that are implemented by each contractor are influenced by the business circumstances, aims, and objectives of each contractor.

\section{References}

1. W.D. Guth and A. Ginsberg, Str. Man. J. 11(4): 5-15 (1990)

2. J.G. Covin and D.P. Slevin, Ent. Theo. Prac. 16(1): 7-25 (1991)

3. R.D. Ireland, J.G. Covin, and D.F. Kuratko, Ent. Theo. Prac. 33(1): 19-46 (2009)

4. A. Özdemirci, Procedia - Soc. Behav. Sci. 24: 611-626 (2011)

5. S. Peltola, Bus. Hor. 55: 43-51 (2012)

6. R. van Wyk and M. Adonisi, South African J. Bus. Man. 43(3): 65-78 (2012)

7. D.M. Gann and A.J. Salter, Research Policy 29: 955-972 (2000)

8. P. Barrett and M. Sexton, British Journal of Management 17(4): 331-346 (2006)

9. F. Blindenbach-Driessen and J. van den Ende, Research Policy 35(4): 545-561 (2006)

10. D. Dvir, A. Sadeh, and A. Malach-Pines, Pro. Man. J. 37(5): 36-48 (2006)

11. P.M. Bosch-Sijtsema and T.J.B.M. Postma, J. Prod. Innov. Man. 26(1): 58-70 (2009)

12. H. Setiawan, Corporate Entrepreneurship Capability Model for Contractors, in School of Energy, Geoscience, Infrastructure and Society, Heriot Watt University: Edinburgh, United Kingdom (2015)

13. M.C. Paulk, et al., Capability Maturity Model ${ }^{S M}$ for Software, Version 1.1, Carnegie Mellon University: Pittsburgh, Pennsylvania (1993)

14. H. Setiawan and B. Erdogan, Int. J. Cons. Man. (to be published)

15. G.T. Lumpkin and G.G. Dess, Ac. Man. Rev. 21(1): 135-172 (1996) 